\title{
Study on Influence of Internal Working Models and Gender Differences on Addiction of Social Network Sites in Japanese University Students
}

\author{
Akihito Fujimori ${ }^{*}$, Tasuku Yamazaki², Mayo Sato ${ }^{2}$, Hideki Hayashi' ${ }^{1}$, Yoji Fujiwara ${ }^{3}$, \\ Taisuke Matsusaka ${ }^{4}$ \\ ${ }^{1}$ Kawasaki University of Medical Welfare, Okayama, Japan \\ ${ }^{2}$ Meiji University of Integrative Medicine, Kyoto, Japan \\ ${ }^{3}$ Takahashi, Okayama, Japan \\ ${ }^{4}$ Manaboshi Clinic, Okayama, Japan \\ Email: fujimori@koto.kpu-m.ac.jp
}

Received 5 September 2015; accepted 2 November 2015; published 5 November 2015

Copyright (C) 2015 by authors and Scientific Research Publishing Inc.

This work is licensed under the Creative Commons Attribution International License (CC BY). http://creativecommons.org/licenses/by/4.0/

c) (i) Open Access

\section{Abstract}

In recent decades, social network sites (SNSs) have become more popular and SNSs addiction has become a serious social problem. However, few studies have examined the effect of a person's internal working model (IWM) on addiction, which determine how attachment processes operate throughout the life course. This study aims at investigating the influence of IWMs and the psychological state, particularly loneliness and interpersonal trust, and of gender differences on addiction of SNSs in Japanese university students. Participants were 284 undergraduates in Japan (130 males, 154 females) who were evaluated with an original questionnaire about SNSs addiction, the UCLA Loneliness Scale, Interpersonal Trust Scale, and Internal Working Model Scale. We conducted multiple regression analyses by setting the entry method, one of which was forced entry, to examine the relationship between the dependent variable (SNSs addiction) and the independent variables (other factors) in each gender. The results show that SNSs addiction is influenced by an ambivalent attachment style (males, $\beta=.19$; females $\beta=.36$ ) and utilization time (males, $\beta=.32$; females $\beta=.32$ ) in both genders. To compare gender differences, we examined the structural equation modeling. The results show that only the influence of an ambivalent attachment style is significantly different between males and females $(z=5.04, p<.01)$, suggesting that such an attachment style predicts SNSs addiction. Because females tend to use SNSs as interaction tools, those with a high ambivalent style may become preoccupied with peer group membership. To prevent

\footnotetext{
*Corresponding author.
}

How to cite this paper: Fujimori, A., Yamazaki, T., Sato, M., Hayashi, H., Fujiwara, Y., \& Matsusaka, T. (2015). Study on Influence of Internal Working Models and Gender Differences on Addiction of Social Network Sites in Japanese University Students. Psychology, 6, 1832-1840. http://dx.doi.org/10.4236/psych.2015.614179 
SNSs addiction, it is important that children form stable attachment relationships with parents/ caregivers when young. Regarding clinical implications, if counseling or psychotherapy is employed for people with SNSs addiction, it is important to assess the attachment style, and that therapy work toward changing an ambivalent style to a stable one.

\section{Keywords}

\section{Social Network Sites (SNSs), SNSs Addiction, Internal Working Models (IWMs), Ambivalence Type, Gender Differences}

\section{Introduction}

In recent decades, the use of social network sites (SNSs) has become more popular. SNSs are defined as webbased services that allow individuals to construct a public or semi-public profile within a bounded system, articulate a list of other users with whom they share a connection, and view and traverse their list of connections and those made by others within the system (Boyd \& Ellison, 2008).

Regarding the positive aspects of SNS use, early studies (Barak \& Gluck-Ofri, 2007) indicated that SNSs provide a positive environment in which the lonely, socially anxious adolescent can express his/her feelings and obtain empathy from others. It has been recognized that SNSs may be the perfect place for shy people to converse with friends and develop communication skills to help them conquer their social communication difficulties (Ryan \& Xenos, 2011). Furthermore, it has been indicated that, given that learning about others and disclosing personal information often leads to greater intimacy, using SNSs that allow personal information exchanges may facilitate relational development (Baker \& Oswald, 2010). Within the narrow limits of Facebook users, it was found that to interact with measures of psychological well-being, suggesting that it might provide greater benefits for users who experience low self-esteem and low life satisfaction (Ellison, Steinfield, \& Lampe, 2007). Moreover, the number of a student's Facebook friends was negatively associated with emotional and academic adjustment among first-year students, but positively related to social adjustment and attachment to institution among upper-class students (Kalpidou, Costin, \& Morris, 2011).

Although it was found that the manner in which SNSs were used differed, those who use them more frequently for social communication reported higher levels of well-being than those who used them less often for this purpose (Wang, Jackson, Gaskin, \& Wang, 2014). In particular, they use SNSs as a method of compensating for their shyness and anxiety when they have to communicate with someone face to face. Another important positive aspect is that there is time to consider one's responses or to make assertions in a simulated turn-taking environment, which provides a more or less level playing field and enhances one's self-esteem.

However, there are negative aspects to SNSs use. Since the late 1990s, when use of the Internet began to spread, uneasiness about the risk was overlooked for convenience. Greater use of the Internet was associated with a decline in a person's communication with family members, a decline in the size of their social circle, and an increase in their depression and loneliness (Kraut et al., 1998). Moreover, an early study indicated that Internet use might decrease social well-being, even though it was often used as a communication tool (Apaolaza, Hartmann, Medina, Barrutia, \& Echebarria, 2013). Regarding SNSs, the frequency of SNS use was linked to a higher social self-concept, whereas investment in SNSs was associated with lower self-esteem and a higher depressed mood (Corey, Blomfield, \& Bonnie, 2014). Simultaneously, some researchers (Larry, 2012) noted that many adolescents worry that they are missing out on something when they are unplugged in today's networked society. Thus, it appears that the number of adolescents who use and/or are addicted to SNSs has increased in the past few years. In fact, SNSs addiction has become a serious social problem (Larry, 2012). Some studies (Ko et al., 2006) showed that the characteristics of a technology addictive personality are impulsivity and social deviance.

In general, there might be a family function issue or attachment problem in addiction or substance abuse or conduct disorder conditions. In the area of alcoholism, Mothersead, Kivlighan, and Wynkoop (1998) suggested that parental alcoholism is related to family dysfunction. Moreover, as the level of family dysfunction increases, secure attachment decreases. 
Concerning SNSs, in Korea, Baek, Bae, and Jang (2013) showed that dependency on parasocial relationships is positively related with loneliness but negatively correlated with interpersonal distrust, whereas dependency on social relationships is negatively correlated with loneliness but positively related with trust. However, more dependency on both social and parasocial relationships is positively related to SNSs addiction. Therefore, the internal state, particularly interpersonal trust and loneliness, are important factors in a person using SNSs. Moreover, an early study (Morahan-Martin \& Schumacher, 2000) showed that male Internet addiction was significantly higher than female addiction.

Thus, the present study focuses on the influence of loneliness, interpersonal trust, internal working models (IWMs; the foundation for understanding how attachment processes operate in adult relationships), and gender differences on SNS addiction.

\subsection{Loneliness and the IWM Concept in Relation to SNSs Addiction}

To sum up the abovementioned studies, SNSs can become a good or a bad tool depending on how they are used. If that is the case, then a person's tendency toward SNSs addiction may be influenced by intrapersonal psychological states or functions.

An early study showed that people who were lonely could develop strong compulsive Internet-use behavior resulting in negative life outcomes (e.g., harming other significant activities such as work, school, or significant relationships) instead of relieving their original problems (Kim, LaRose, \& Peng, 2009).

In particular, for about half a century, attachment theory was considered important in explaining how a person relates to others. Attachment is defined as the instinct for an affectional bond between a child and his/her parental figure, and is said to have an impact on a person's later human relationships. Secure attachment is related to adaptation, whereas insecure attachment is related to maladaptation (Bowlby, 1969).

Bowlby believed that attachment behaviors are instinctive and will be activated by any conditions that appear to threaten the achievement of proximity, such as separation, insecurity, and fear. Attachment behaviors are then transferred to different relationship partners throughout the life span. Moreover, he suggested the IWM concept is the foundation for understanding how attachment processes operate throughout a person's life. IWMs develop in the context of primary caregivers during childhood and then generalize to other types of social relationships during adulthood. Following Bowlby, Ainsworth and Bell (1970) classified three IWM styles: secure (type B), avoidance (type A), and ambivalent (type C). They concluded that these attachment styles were the result of a child's early interactions with the caregiver. Type B people feel confident that the attachment figure will be available to meet their needs. They use the attachment figure as a safe base for exploring the environment and seek the attachment figure in times of distress. Type A people do not orient themselves to their attachment figure while investigating the environment. They are very independent of the attachment figure both physically and emotionally. The attachment figure may withdraw from helping during difficult tasks and often be unavailable during times of emotional distress. Type $\mathrm{C}$ people adopt an ambivalent behavioral style toward the attachment figure. They commonly exhibit clingy and dependent behavior, but reject the attachment figure when they engage in interaction. Accordingly, they exhibit difficulty in moving away from the attachment figure to explore new surroundings. When distressed, it is difficult to soothe them, and they are not comforted by interaction with the attachment figure. This behavior results from an inconsistent level of response to their needs from the primary caregiver.

We think that IWMs influence not only a person's relationship with partners but also SNSs use. One study indicated that attachment anxiety was linked to propositioning sexual activity through text messaging for individuals in a relationship (Weisskirch \& Delevi, 2009). Another study reported an association between anxious attachment and sending sexual text messages, and between avoidant attachment and sending both texts and pictures with sexual content (Droun \& Landgraff, 2012).

But the relationship between addiction and IWMs has thus far never been studied. Thus, this study focuses on the impact that loneliness and IWMs have on SNSs addiction.

\subsection{Gender Differences in SNSs Use}

Several studies have investigated gender differences in SNSs use. Females appear to use SNSs to communicate with members of their peer group, whereas males appear to use them for the purposes of social compensation, 
learning, and social identity gratification (Kim, Kim, \& Nam, 2010). Furthermore, research has indicated that males tend to disclose more personal information on SNS sites relative to females (Jelicic, Bobek, Phelps, Lerner, \& Lerner, 2007). Furthermore, more females were specifically found to use MySpace compared with males (Wise, Alhabash, \& Park, 2010). Moreover, usage patterns were found to differ between the genders as a function of personality. Unlike females with neurotic traits, males with neurotic traits were found to be more frequent SNS users (Correa, Hinsley, \& de Zuniga, 2010). In addition, it was shown that males specifically were more likely to be addicted to SNS games compared with females (Zhou, 2010). This result is in line with the finding that males in general are a population at risk for developing an addiction to playing online games (Kuss \& Griffiths, 2012).

However, little attention has been paid to gender differences in terms of the influence of IWMs and the psychological state (loneliness and interpersonal trust) on SNSs addiction.

\subsection{The Present Study}

We believe that IWMs may help to further explain SNSs addiction. Thus, the purpose of the present study is to examine the influence of IWMs and the psychological state, particularly loneliness and interpersonal trust, and of gender differences on SNSs addiction in Japanese university students.

\section{Methods}

\subsection{Sample}

The current survey study was conducted at the Ethical Review Committee of Hanazono University. We selected university students in Japan as our subjects. We told all participants that their responses would be kept confidential and only summary information would be presented. Furthermore, we assured them of complete anonymity. Overall, 284 students (males 130, females 154), age ranging from 18 to 29 (SD 1.2), volunteered to participate in our study, and to prevent any leaking of personal information via survey assistants, participants responded anonymously to the survey materials.

\subsection{Measurements}

\subsubsection{Original Questionnaire for Evaluating SNSs Addiction and Types of SNSs}

Previous studies of SNSs have had limitations, one of which is an ambiguous definition of SNSs. For instance, an earlier study involving SNSs used just the term "Internet use" and not "membership system". Thus, the present study established the following definition (Boyd \& Ellison, 2008) of eight types of SNSs: Twitter, Facebook, LINE, mixi, GREE, Ameba, Skype, KakaoTalk, and subjects were also free to list any types of SNSs (if any) that were not included among the eight types. Next, we adopted this as the definition of SNSs.

Regarding addiction, Griffiths (1995) defined the concept of a generic technology addiction that can apply to any computer-based technology and as nonchemical (behavioral) addictions those that involve human-machine interaction. Furthermore, Young (1996) suggested that addicts become hooked on specific applications on computers. Then, based on the above definitions, SNSs addiction can be regarded as a state being unable to bear the uneasiness a person feels when he/she cannot use SNSs. Thus, SNSs addiction was evaluated according to the original question: "How would you feel if you could not use SNSs anymore?" and scored on a 6-point scale (not uneasy-extremely uneasy). We also asked participants about the time they spent on SNSs usage: "How long do you use SNSs a day on average?” and scored on a 4-point scale ( $1=0$ - 2 hours, $2=2$ - 4 hours, $3=4$ - 6 hours, $4=$ more than 6 hours).

\subsubsection{Attachment}

To assess individual differences in IWMs, participants completed the Japanese translation version of the Internal Working Model Scale (IWMS; Toda, 1988), which was based on the Adult Attachment Scale (Hazan \& Shaver, 1987), and which measures 18 items scored on a 6-point scale that includes three factors with six items each. The Avoidant Attachment subscale assesses a person's feeling that others reject him/her and that the person cannot expect the support of others $(\alpha=.74)$. The Secure Attachment subscale assesses a person's feeling that he/she values the presence and support of others, and that others are responsive to him/her $(\alpha=.91)$. The Ambi- 
valent Attachment subscale assesses a person's ambivalent feeling of trust in and distrust toward others, and strong feeling of self-insufficiency $(\alpha=.82)$. This scale grasped three factors as a characteristic and measures individual differences in IWMs by a relative comparison among individuals.

\subsubsection{Loneliness}

Participants completed the revised UCLA Loneliness Scale (UCLA) to evaluate loneliness. This scale, which was developed by Russell (1982), comprises 20 items scored on a 6-point scale. The reliability $(\alpha=.88)$ and validity of the Japanese version of the UCLA were confirmed by Moroi (1992).

\subsubsection{Interpersonal Trust}

Participants completed the Interpersonal Trust Scale (ITS) to evaluate interpersonal trust (Horii \& Tsuchiya, 1995). Developed on the basis of Rotter's findings (1967), the scale comprises 17 items $(\alpha=.81)$ scored on a 5-point scale. This scale does not evaluate specific interpersonal trust but rather general trust (e.g., A person is basically honest).

\subsection{Statistical Analysis}

First, a Pearson correlation coefficient was performed in the overall sample preliminary analysis.

Then, multiple regression analyses were performed to examine the relationship between the dependent variable (SNSs addiction) and the independent variables (other factors).

All analyses were performed using SPSS (version 17.0) for Windows (SPSS Inc., Chicago, IL, USA).

\section{Results}

\subsection{Preliminary Analysis}

Descriptive information on measures that were used in this study is presented in Table 1 . We conducted several preliminary analyses to determine the attachment style (avoidant, secure, and ambivalent), personal traits (loneliness, interpersonal trust), and SNSs use (utilization time, SNSs addiction), as well as compared participants' gender and age by t-tests. The results showed that males and females differ on secure attachment style $(p<.05)$, loneliness $(p<.01)$, interpersonal trust $(p<.01)$, utilization time $(p<.01)$, and SNSs addiction $(p<.05)$. However, on age, there were no significant differences except for ambivalent attachment style $(p<.05)$. These results indicated that different structures in IWMs and psychological states influence SNSs addiction between males and females.

Table 1. Descriptive statistics and results of independent t-test comparing sex and age.

\begin{tabular}{|c|c|c|c|c|c|}
\hline \multirow{2}{*}{$\mathrm{N}=284$} & \multicolumn{3}{|c|}{ Basic statistic } & \multicolumn{2}{|c|}{ Preliminary analysis } \\
\hline & Mean & $S D$ & Range & Sex $t$ & Age $r$ \\
\hline \multicolumn{6}{|l|}{ Attachment style } \\
\hline Avoidant & 18.99 & 5.10 & $6-35$ & -.52 & .06 \\
\hline Secure & 21.37 & 6.04 & $6-36$ & $-2.10^{*}$ & .03 \\
\hline Ambivalent & 21.65 & 5.51 & $6-36$ & -1.36 & $-.18^{*}$ \\
\hline \multicolumn{6}{|l|}{ Psychological state } \\
\hline Lonelieness & 38.71 & 9.28 & $20-74$ & $3.77^{* *}$ & -.03 \\
\hline Interpersonal Trust & 47.20 & 9.10 & $19-78$ & $-2.97^{* *}$ & -.11 \\
\hline \multicolumn{6}{|l|}{ Related SNSs } \\
\hline Utilization time & 2.12 & 1.08 & $1-4$ & $-2.68^{* *}$ & -.11 \\
\hline SNSs addiction & 3.62 & 1.62 & $1-6$ & $-2.26^{*}$ & -.10 \\
\hline
\end{tabular}

Note: ${ }^{* *} p<.01,{ }^{*} p<.05$. 


\subsection{Influence of Psychological State and IWMs Gender Differences on SNSs Addiction}

Preliminary analysis revealed gender differences for secure attachment style, loneliness, interpersonal trust, and related to SNSs (utilization time, SNSs addiction). Thus, using multiple group structural equation modeling, we examined the gender differences of structures. First, Table 2 shows the results of the partial correlations separated by sex. In males, there were significant correlations between loneliness and avoidant $(r=.44, p<.01)$, secure $(r=-.58, p<.01)$, and ambivalent $(r=.24, p<.01)$. Furthermore, interpersonal trust and avoidant were significantly correlated $(r=-.32, p<.01)$. Regarding SNSs, SNSs addiction and ambivalent $(r=.22, p<.05)$, and utilization time $(r=.34, p<.01)$ were significantly correlated.

In females, there were correlations between loneliness and avoidant $(r=.46, p<.01)$, secure $(r=-.55, p$ $<.01)$, and ambivalent $(r=.29, p<.01)$. Furthermore, interpersonal trust and avoidant $(r=-.38, p<.01)$, secure $(r=.20, p<.05)$, ambivalent $(r=-.32, p<.01)$, and loneliness $(r=-.40, p<.01)$ were significantly correlated. Regarding SNSs, SNSs addiction and ambivalent $(r=.39, p<.01)$, and utilization time $(r=.36, p<.01)$ were significantly correlated. In comparison with males, females showed a significant correlation between ambivalent and utilization time $(r=.20, p<.05)$.

Next, we conducted multiple regression analyses by setting the entry method, one of which is forced entry, to examine the relationship between the dependent variable (SNSs addiction) and the independent variables (other factors) for each gender. The results showed that SNSs addiction was influenced by an ambivalent attachment style (males $\beta=.19$; females $\beta=.36$ ) and utilization time (males $\beta=.32$; females $\beta=.32$ ) in both genders.

Furthermore, to compare the gender differences in the above structure, we examined the structural equation modeling. The results showed that only the influence of ambivalent was significantly different between males and females $(z=5.04, p<.01)$ (Table 3$)$.

Table 2. Partial correlations separated by gender.

\begin{tabular}{|c|c|c|c|c|c|c|c|}
\hline \multirow{2}{*}{$\begin{array}{c}\text { Males } \\
\mathrm{N}=130\end{array}$} & \multicolumn{3}{|c|}{ Attachment style } & \multicolumn{2}{|c|}{ Psychological state } & \multicolumn{2}{|c|}{ Related SNSs } \\
\hline & Avoidant & Secure & Ambivalent & Loneliness & $\begin{array}{c}\text { Interpersonal } \\
\text { Trust }\end{array}$ & $\begin{array}{l}\text { Utilization } \\
\text { time }\end{array}$ & $\begin{array}{c}\text { SNSs } \\
\text { addiction }\end{array}$ \\
\hline Avoidant & - & & & & & & \\
\hline Secure & -.09 & - & & & & & \\
\hline Ambivalent & $.21^{*}$ & -.11 & - & & & & \\
\hline Loneliness & $.44^{* *}$ & $-.58^{* *}$ & $.24^{* *}$ & - & & & \\
\hline Interpersonal Trust & $-.32^{* *}$ & .04 & -.10 & -.13 & - & & \\
\hline Utilization time & .08 & -.11 & .13 & .12 & -.07 & - & \\
\hline SNSs addiction & .02 & -.02 & $.22^{*}$ & .04 & -.03 & $.34^{* *}$ & - \\
\hline \multirow{2}{*}{$\begin{array}{l}\text { Females } \\
\mathrm{N}=154\end{array}$} & \multicolumn{3}{|c|}{ Attachment style } & \multicolumn{2}{|c|}{ Psychological state } & \multicolumn{2}{|c|}{ Related SNSs } \\
\hline & Avoidant & Secure & Ambivalent & Loneliness & $\begin{array}{c}\text { Interpersonal } \\
\text { Trust }\end{array}$ & $\begin{array}{l}\text { Utilization } \\
\text { time }\end{array}$ & $\begin{array}{c}\text { SNSs } \\
\text { addiction }\end{array}$ \\
\hline Avoidant & - & & & & & & \\
\hline Secure & $-.19^{*}$ & - & & & & & \\
\hline Ambivalent & $.26^{* *}$ & $-.18^{*}$ & - & & & & \\
\hline Loneliness & $.46^{* *}$ & $-.55^{* *}$ & $.29^{* *}$ & - & & & \\
\hline Interpersonal Trust & $-.38^{* *}$ & $.20 *$ & $-.32^{* *}$ & $-.40^{* *}$ & - & & \\
\hline Utilization time & .12 & .06 & $.20^{*}$ & -.01 & .14 & - & \\
\hline SNSs addiction & .02 & -.10 & $.39^{* *}$ & .09 & -.04 & $.36^{* *}$ & - \\
\hline
\end{tabular}

Note: ${ }^{* *} p<.01,{ }^{*} p<.05$ 
Table 3. Multiple regression results predicting SNSs addiction from attachment style, SNSs utilization time, loneliness, and interpersonal trust.

\begin{tabular}{ccccc}
\hline & All data & males & females & males-females \\
\cline { 2 - 4 } & Adj $\beta$ & Adj $\beta$ & Adj $\beta$ & z \\
Attachment style & & & & 1.38 \\
Avoidant & -.06 & -.04 & -.09 & $2.83^{* *}$ \\
Secure & -.04 & .02 & -.08 & $5.04^{* *}$ \\
Ambivalent & $.27^{*}$ & $.19^{* *}$ & $.36^{* *}$ & 1.79 \\
Psychological state & & & .02 & $5.23^{* *}$ \\
Lonelieness & -.02 & -.02 & .11 & $.32^{* *}$ \\
Interpersonal Trust & .04 & .00 & & .01 \\
Related SNSs & $.32^{* *}$ & & &
\end{tabular}

\section{Discussion}

This is the first study to examine the influence of IWMs and the psychological state, particularly loneliness and interpersonal trust, and of gender differences on SNSs addiction in Japanese university students. A positive relationship was observed between SNSs addiction and SNSs utilization. This result showed that we could measure the degree of SNSs addiction accurately.

Preliminary analysis indicated that females had significantly higher SNSs addiction and SNSs utilization time scores. This result differs from earlier studies, which reported that Internet addiction is significantly higher in males than females (Morahan-Martin \& Schumacher, 2000). The reason for this difference may be due to SNSs being different from the Internet, in that SNSs are mainly used as a tool for communicating with others, and therefore, females users make more use of them (Kim et al., 2010). Thus, as far as SNSs use, females have a tendency toward SNSs addiction. This explanation is supported by the finding that there were no differences between the genders in the ambivalent attachment style score.

Furthermore, we found that an ambivalent attachment style influenced SNSs addiction. These results may indicate that a person who has a conflict with others may make more use of SNSs as a solution to his/her problems or to decrease his/her anxiety about communicating with others. This study showed that SNSs may not help improve an unsecure attachment style so that it becomes a secure attachment style, although SNSs provide the opportunity to communicate with others through "exploratory behavior". In other words, this study showed that an ambivalent attachment style predicts SNSs addiction. To prevent such addiction, it is important that a child forms stable attachment relationships with parents/caregivers.

In the regression models, there were no significant effects of psychological state on SNSs addiction. This result revealed that loneliness and/or interpersonal trust did not have a significant impact on SNSs addiction.

Another key finding was that females' SNSs addiction was significantly more influenced by an ambivalent attachment style than males'. A possible contributor to this result might have been the gender difference for SNSs attitude. Because females tend to use SNSs as interaction tools (Kim et al., 2010), those who have a high ambivalent style might be preoccupied with peer group membership. Thus, an ambivalent attachment style might cause SNSs addiction.

Regarding clinical implications, if we employ counseling or psychotherapy for people with SNSs addiction, it is important to assess their attachment style, and that therapy aim at changing an ambivalent attachment style to a stable one. This approach might lead to less SNSs addiction.

The current study has several important limitations. First, we must examine more carefully what SNSs addiction is. Currently, there are no scales to assess the multiple dimensions of SNSs addiction. We only asked the participants, "How would you feel if you could not use SNSs anymore?” Thus, there is a possibility that we only 
assessed one aspect of SNSs addiction. In a future study, we will investigate other factors that may drive SNSs addiction. Moreover, what must not be forgotten is that other psychological state factors influence SNSs addiction. In future research, we should explore more limited kinds of SNSs that are used only as interaction tools and not for games.

\section{References}

Ainsworth, M., \& Bell, S. (1970). Attachment, Exploration, and Separation: Illustrated by the Behavior of One-Year-Olds in a Strange Situation. Child Development, 41, 49-67. http://dx.doi.org/10.2307/1127388

Apaolaza, V., Hartmann, P., Medina, E., Barrutia, J. M., \& Echebarria, C. (2013). The Relationship between Socializing on the Spanish Online Networking Site Tuenti and Teenagers' Subjective Wellbeing: The Roles of Self-Esteem and Loneliness. Computers in Human Behavior, 29, 1282-1289. http://dx.doi.org/10.1016/j.chb.2013.01.002

Baek, Y., Bae, Y., \& Jang, H. (2013). Social and Parasocial Relationships on Social Network Sites and Their Differential Relationships with Users’ Psychological Well-Being. Cyberpsychology, Behavior, and Social Networking, 16, 512-517. http://dx.doi.org/10.1089/cyber.2012.0510

Baker, L., \& Oswald, D. (2010). Shyness and Online Social Networking Services. Journal of Social and Personal Relationships, 27, 873-889. http://dx.doi.org/10.1177/0265407510375261

Barak, A., \& Gluck-Ofri, O. (2007). Degree and Reciprocity of Self-Disclosure in Online Forums. Cyberpsychology, Behavior, and Social Networking, 10, 407-417. http://dx.doi.org/10.1089/cpb.2006.9938

Bowlby, J. (1969). Attachment: Attachment and Loss Volume One. New York: Basic Books.

Boyd, D., \& Ellison, N. (2008). Social Network Sites: Definition, History, and Scholarship. Journal of Computer-Mediated Communication, 13, 210-230. http://dx.doi.org/10.1111/j.1083-6101.2007.00393.x

Corey, J., Blomfield. N., \& Bonnie, B. (2014). Social Networking Site Use: Linked to Adolescents’ Social Self-Concept, Self-Esteem, and Depressed Mood. Australian Journal of Psychology, 66, 56-64. http://dx.doi.org/10.1111/ajpy.12034

Correa, T., Hinsley, A. W., \& de Zuniga, H. G. (2010). Who Interacts on the Web?: The Intersection of Users' Personality and Social Media Use. Computers in Human Behavior, 26, 247-253. http://dx.doi.org/10.1016/j.chb.2009.09.003

Droun, M., \& Landgraff, C. (2012). Texting, Sexting, and Attachment in College Students' Romantic Relationship. Computers in Human Behavior, 28, 444-449. http://dx.doi.org/10.1016/j.chb.2011.10.015

Ellison, N., Steinfield. C., \& Lampe, C. (2007). The Benefits of Facebook “Friends”: Social Capital and College Students' Use of Online Social Network Sites. Journal of Computer-Mediated Communication, 12, 1143-1168. http://dx.doi.org/10.1111/j.1083-6101.2007.00367.x

Griffiths, M. (1995). Technological Addictions. Clinical psychological forum, 71, 14-19.

Hazan, C., \& Shaver, P. (1987). Romantic Love Conceptualized as an Attachment Process. Journal of Personality and Social Psychology, 52, 511-524. http://dx.doi.org/10.1037/0022-3514.52.3.511

Horii, T., \& Tsuchiya, E. (1995). A Study of the Relationship between the Earliest Recollection and Interpersonal Trust. The Japanese Journal of Personality, 3, 27-36.

Jelicic, H., Bobek, D.L., Phelps, E., Lerner, R. M., \& Lerner, J. V. (2007). Using Positive Youth Development to Predict Contribution and Risk Behaviors in Early Adolescence: Findings from the First Two Waves of the 4-H Study of Positive Youth Development. International Journal of Behavioral Development, 31, 263-273. http://dx.doi.org/10.1177/0165025407076439

Kalpidou, M., Costin, D., \& Morris, J. (2011). The Relationship Between Facebook and the Well-Being of Undergraduate College Students. Cyberpsychology, Behavior and Social Networking, 14, 183-189. http://dx.doi.org/10.1089/cyber.2010.0061

Kim, J., LaRose, R., \& Peng, W. (2009). Loneliness as the Cause and the Effect of Problematic Internet Use: The Relationship between Internet Use and Psychological Well-Being. Cyberpsychology \& Behavior, 12, 541-455. http://dx.doi.org/10.1089/cpb.2008.0327

Kim, J. H., Kim, M. S., \& Nam, Y. (2010). An Analysis of Self-Construals, Motivations, Facebook Use, and User Satisfaction. International Journal of Human-Computer Interaction 26, 1077-1099. http://dx.doi.org/10.1080/10447318.2010.516726

Ko, C.-H., Yen, J.-Y., Chen, C.-C., Chen, S.-H., Wu, K., Yen, C.-F. (2006). Tridimensional Personality of Adolescents with Internet Addiction and Substance Use Experience. Canadian Journal of Psychiatry, 51, 887-894.

Kraut, R., Patterson, M., Lundmark, V., Kiesler, S., Mukopadhyay, T., \& Scherlis, W. (1998). Internet Paradox. A Social Technology that Reduces Social Involvement and Psychological Well-Being? American Psychological Association, 53, 1017-1031. 
Kuss, D. J., \& Griffiths, M. D. (2012). Internet Gaming Addiction: A Systematic Review of Empirical Research. International Journal of Mental Health and Addiction, 10, 278-296. http://dx.doi.org/10.1007/s11469-011-9318-5

Larry, D. (2012). Idisorder: Understanding Our Obsession With Technology and Overcoming Its Hold on Us. United Kingdom: Griffin Press.

Morahan-Martin J., \& Schumacher, P. (2000). Incidence and Correlates of Pathological Internet Use among College Students. Computers in Human Behavior, 16, 13-29. http://dx.doi.org/10.1016/S0747-5632(99)00049-7

Moroi, K. (1992). Dimensions of the Revised UCLA Loneliness Scale. Faculty of Humanities and Social Sciences, 42, 23-51.

Mothersead, P., Kivlighan, D., \& Wynkoop, T. (1998). Attachment, Family Dysfunction, Parental Alcoholism, and Interpersonal Distress in Late Adolescence: A structural model. Journal of Counseling Psychology, 45, 196-203. http://dx.doi.org/10.1037/0022-0167.45.2.196

Rotter, J. (1967). A New Scale for the Measurement of Interpersonal Trust. Journal of Personality, 35, $651-665$. http://dx.doi.org/10.1111/j.1467-6494.1967.tb01454.x

Russell, D. (1982). The Measurement of Loneliness. In L. Peplau, \& D. Perlman (Eds.), Loneliness: A Sourcebook of Current Theory, Research and Therapy (pp.81-104). United States: Wiley.

Ryan, T., \& Xenos, S. (2011). Who Uses Facebook? An Investigation into the Relationship between the Big Five, Shyness, Narcissism, Loneliness, and Facebook Usage. Computers in Human Behavior, 27, 1658-1664. http://dx.doi.org/10.1016/j.chb.2011.02.004

Toda, K. (1988). Basic Interpersonal Relationships and Attachment Style in the Late Adolescence-Examination from Working Models. 52nd Conference of the Japanese Psychological Association, Hiroshima, 8 October 1988, 27.

Wang, J., Jackson, L., Gaskin, J., \& Wang, H. (2014). The Effects of Social Networking Site (SNS) Use on College Students' Friendship and Well-Being. Computers in Human Behavior, 37, 229-236. http://dx.doi.org/10.1016/j.chb.2014.04.051

Weisskirch, S., \& Delevi, R. (2009). "Sexting” and Adult Romantic Attachment. Computers in Human Behavior, 27, 1697-1701. http://dx.doi.org/10.1016/j.chb.2011.02.008

Wise, K., Alhabash, S., \& Park, H. (2010). Emotional Responses during Social Information Seeking on Facebook. Cyberpsychology, Behavior, and Social Networking, 13, 555-562. http://dx.doi.org/10.1089/cyber.2009.0365

Young, K. (1996). Psychology of Computer Use: Xl. Addictive Use of the Internet: A Case That Breaks the Stereotype. Psychological Reports, 79, 899-902. http://dx.doi.org/10.2466/pr0.1996.79.3.899

Zhou, S. X. (2010). Gratifications, Loneliness, Leisure Boredom and Self-Esteem as Predictors of SNS-Game Addiction and Usage Pattern among Chinese College Students. M.S. Thesis, Hong Kong: Chinese University of Hong Kong. 